\title{
Prevalence of Undiagnosed Cardiovascular Risk Factors in Adults Aged 20 - 40: A Cross-Sectional Study in 2016 in Jeddah, Saudi Arabia
}

\author{
Faisal Saed Alharthi ${ }^{\mathrm{a}}$, e, Jamilah Saad Alrahimi ${ }^{\mathrm{b}}$, Abdulrahman Ali Alotaibi ${ }^{\mathrm{a}}$, Daniah Ahmed Alhamdic, \\ Bashair Mohammed Ibrahim ${ }^{\mathrm{c}}$, Yasmina Aymen Badeeb ${ }^{\mathrm{d}}$
}

\begin{abstract}
Background: Cardiovascular diseases (CVDs) are the first leading cause of death worldwide. In Saudi Arabia, CVDs are the major killers with a mortality rate of $46 \%$. CVD risk factors are not exclusive to old populations. Thus, the purpose of this study was to approximately find the prevalence of these risk factors, particularly high blood pressure (HBP), high blood glucose (HBG), obesity, and smoking.
\end{abstract}

Methods: This cross-sectional was conducted in May 2016 and took place in the Ambulatory Care Center of King Abdulaziz Medical City, Jeddah. We used a non-probability convenience sampling technique where only individuals aged 20 - 40 who were free of medical illnesses were included. We excluded pregnant women and people on medications that might interfere with our measurements. We obtained a brief history and measured blood pressure, blood glucose, height and weight. Data analysis was done in form of frequencies. Chi-square test was utilized to compare qualitative variables. $\mathrm{P}<0.05$ was used to determine statistical significance.

Results: A total of 507 participants were included $(76.3 \%$ males and $23.7 \%$ females). All participants were between 20 and 40 with a mean age of $31.6 \pm 6.06 \mathrm{SD}$. We found the prevalence of undiagnosed HBP to be $8.3 \%$ and males showed a significantly higher percentage $(\mathrm{P}<$ 0.001 ) when compared to females. HBG prevalence was only $0.6 \%$. Regarding body mass index, the prevalence of overweight and obesity together was $66.3 \%$ and males showed significantly higher percentage in falling in this category $(\mathrm{P}<0.001)$. Smoking prevalence was $37.9 \%$ with a significantly higher percentage among males $(\mathrm{P}<0.001)$.

Conclusion: CVD risk factors are apparently quite common in young adults. Efforts must be made to increase the public awareness regard-

Manuscript submitted June 7, 2017, accepted June 15, 2017

aKing Saud bin Abdulaziz University for Health Sciences, Jeddah, Saudi Arabia

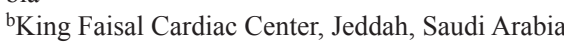

${ }^{\mathrm{c}}$ King Abdulaziz University, Jeddah, Saudi Arabia

${ }^{\mathrm{d} B a t t e r j e e ~ M e d i c a l ~ C o l l e g e, ~ J e d d a h, ~ S a u d i ~ A r a b i a ~}$

${ }^{e}$ Corresponding Author: Faisal Saed Alharthi, King Saud bin Abdulaziz Uni-

versity for Health Sciences, Jeddah, Saudi Arabia.

Email: Harthifs@gmail.com

doi: https://doi.org/10.14740/cr566w ing these risk factors. CVDs are not exclusive to old people. Thus, the public should appreciate this fact in order to prevent these risk factors by establishing healthy life-styles.

Keywords: Cardiovascular; Risk factors; Prevalence; Undiagnosed

\section{Introduction}

Cardiovascular diseases (CVDs) are the first leading cause of death worldwide [1]. Between 1990 and 2010, CVDs caused around 12.5 deaths globally. Moreover, the ratio of deaths caused by CVDs among all deaths increased from 1:5 in 1990 to $1: 4$ in 2010 [2]. These terrifying numbers should drag our attention to stop or at least slow the progression of CVDs in order to save more lives.

Most CVD victims are suffering from deteriorating body functions and incompatibility with life. Consequently, victims might have life-threatening situations that may enforce their families to face grief. Fortunately, most of the CVDs are highly related to controllable risk factors, such as hypertension (HTN), diabetes mellitus (DM), and dyslipidemia, or preventable risk factors like smoking, obesity, and physical inactivity [3]. However, people need to be completely aware of these risk factors and their harmful effects in order to start a healthy life-style.

The prevalence of CVD risk factors has been studied worldwide. Many studies addressed the overall prevalence of each risk factor in different populations, whether they were previously healthy or already diagnosed [4-6]. Other studies focused on undiagnosed risk factors but in individuals aged 40 and older [7, 8]. In our opinion, CVD risk factors should be identified earlier in order to prevent its progression and complications, especially with the unhealthy life-styles observed these days.

In the Kingdom of Saudi Arabia, the CVD mortality rate among all causes of death is $46 \%$ [9]. This terrifying percentage might be related to the lack of awareness of cardiovascular risk factors, or people might be affected but not aware about their medical conditions. In the last two decades, smoking and high consumption of unhealthy food have increased in our community, regardless of the fact that they can be easily prevented $[10,11]$. In Jeddah, a research had studied school 
students aged less than 18 years and found affected individuals with different risk factors in different proportions [12].

In our study, we targeted the population that visit the Ambulatory Care Center, King Abdulaziz Medical City, Jeddah, Saudi Arabia, in order to determine the prevalence of undiagnosed CVD risk factors, particularly high blood pressure (HBP), high blood glucose (HBG), obesity, and smoking. To achieve this, we screened adults aged 20 - 40 years in both genders.

\section{Materials and Methods}

\section{Design, setting, participants, and questionnaire}

A cross-sectional study was conducted in May 2016 where data were collected from a campaign conducted at the Ambulatory Care Center, King Abdulaziz Medical City, Jeddah, Saudi Arabia. We screened visitors and provided them with information regarding cardiovascular risk factors. We used a non-probability convenience sampling technique where only individuals who met our criteria were included in the study for data collection. Our inclusion criteria consisted of people aged 20 - 40 in both genders who were free of medical illnesses. A brief questionnaire was completed by each participant about medical history (DM and HTN), smoking status, medications, and family history. We excluded pregnant women and individuals who were taking medications that might interfere with our measurements, such as non-steroidal anti-inflammatory drugs, tricyclic antidepressants, or oral contraceptive pills. An informed written consent was obtained prior to inclusion.

\section{Measurements and definitions}

Blood pressure (BP) measurement was done following American Heart Association recommendations [13]. A BP reading was obtained for each individual. For individuals who had an abnormal first reading, another reading was obtained $10 \mathrm{~min}$ later. We used an electronic vital signs monitor (SureSigns VS3, Philips, Andover, USA) to measure BP. The analysis was based on JNC-8 recommendations to define HBP. We considered any reading as HBP if the systolic blood pressure (SBP) exceeded $140 \mathrm{~mm} \mathrm{Hg}$ and/or the diastolic blood pressure (DBP) exceeded $90 \mathrm{~mm} \mathrm{Hg}$ [14].

Body mass index (BMI) was calculated as weight (kg) divided by the square of height $\left(\mathrm{m}^{2}\right)$. Participants were labeled according to World Health Organization (WHO) categorization as follows: underweight (BMI $\left.<18.5 \mathrm{~kg} / \mathrm{m}^{2}\right)$, normal $(\mathrm{BMI}=$ $\left.18.5-24.9 \mathrm{~kg} / \mathrm{m}^{2}\right)$, overweight $\left(\mathrm{BMI}=25-29.9 \mathrm{~kg} / \mathrm{m}^{2}\right)$, obese class I $\left(B M I=30-34.9 \mathrm{~kg} / \mathrm{m}^{2}\right)$, obese class II $(\mathrm{BMI}=35-$ $\left.39.9 \mathrm{~kg} / \mathrm{m}^{2}\right)$, and obese class III (BMI $\left.\geq 40 \mathrm{~kg} / \mathrm{m}^{2}\right)$ [15]. Weight and height were measured using electrical digital scale with a height rod attached (Seca 703, Seca, Hamburg, Germany).

Blood glucose level was measured using manual glucometer (Precision Xtra, Abbott, IL, USA). All participants were asked about their last meal received. To categorize readings as fasting or random, we depended on the 8-h limit. All participants were labeled according to the cutoff points established
Table 1. Demographic Data and Measurements

\begin{tabular}{lll}
\hline & No. & $\%$ \\
\hline Age $($ mean \pm SD) & $31.6 \pm 6.06$ & \\
Total & 507 & $100 \%$ \\
$\quad$ Male & 387 & $76.3 \%$ \\
$\quad$ Female & 120 & $23.7 \%$ \\
Blood pressure & & \\
$\quad$ SBP/DBP $<140 / 90 \mathrm{~mm} \mathrm{Hg}$ & 465 & $91.7 \%$ \\
$\quad$ SBP/DBP $\geq 140 / 90 \mathrm{~mm} \mathrm{Hg}$ & 42 & $8.3 \%$ \\
Blood glucose & & \\
$\quad$ RBG $<200 \mathrm{mg} / \mathrm{dL}$ & 504 & $99.4 \%$ \\
$\quad$ RBG $\geq 200 \mathrm{mg} / \mathrm{dL}$ & 3 & $0.6 \%$ \\
BMI $\quad$ & \\
$\quad$ Underweight $\left(<18.5 \mathrm{~kg} / \mathrm{m}^{2}\right)$ & 19 & $3.7 \%$ \\
$\quad$ Normal $\left(18.5-24.9 \mathrm{~kg} / \mathrm{m}^{2}\right)$ & 152 & $30 \%$ \\
\hline Overweight $\left(25-29.9 \mathrm{~kg} / \mathrm{m}^{2}\right)$ & 186 & $36.7 \%$ \\
\hline Obese class I $\left(30-34.9 \mathrm{~kg} / \mathrm{m}^{2}\right)$ & 99 & $19.5 \%$ \\
\hline Obese class II $\left(35-39.9 \mathrm{~kg} / \mathrm{m}^{2}\right)$ & 31 & $6.2 \%$ \\
\hline Obese class III $\left(\geq 40 \mathrm{~kg} / \mathrm{m}^{2}\right)$ & 20 & $3.9 \%$ \\
Smoking & & $62.1 \%$ \\
\hline Non-smoker & 315 & $37.9 \%$ \\
\hline Smoker & 192 & \\
\hline
\end{tabular}

SD: standard deviation; SBP: systolic blood pressure; DBP: diastolic blood pressure; RBG: random blood glucose; BMI: body mass index.

by WHO, which are defined as follows: $126 \mathrm{mg} / \mathrm{dL}$ for fasting and $200 \mathrm{mg} / \mathrm{dL}$ for random [16].

\section{Statistical analysis}

IBM SPSS version 19 was utilized for data entry, management and analysis. Descriptive statistics was utilized in form of frequencies and percentages for categorical data, mean of standard deviation for quantitative data if it is normally distributed, or median of quartiles if data are skewed. To compare qualitative variables, we utilized Chi-square test and we used a $\mathrm{P}<$ 0.05 to determine statistical significance.

\section{Results}

A total of 507 participants were included in this study (Table $1)$. The majority of them were males with a sum of 387 participants $(76.3 \%)$ while females were 120 participants $(23.7 \%)$. All participants were between 20 and 40 years old (minimum 20 and maximum 40) with a mean age of 31.6 years and 6.06 standard deviation.

$\mathrm{BP}$ results were divided into two groups. The first group included participants with an SBP $\geq 140 \mathrm{~mm} \mathrm{Hg}$ and/or DBP $\geq 90 \mathrm{~mm} \mathrm{Hg}$. The other group included participants with less 
Table 2. Statistically Significant Gender Comparison

\begin{tabular}{|c|c|c|c|}
\hline \multirow{2}{*}{ Variable } & \multicolumn{2}{|c|}{ Gender of participant } & \multirow{2}{*}{ P-value } \\
\hline & Male, $\mathbf{N}$ (\% within gender) & Female, $\mathbf{N}(\%$ within gender) & \\
\hline $\mathrm{BP}(\mathrm{mm} \mathrm{Hg})$ & & & $<0.001$ \\
\hline $\mathrm{SBP} \geq 140 \mathrm{and} /$ or $\mathrm{DBP} \geq 90$ & $41(10.6 \%)$ & $1(0.8 \%)$ & \\
\hline BMI & & & $<0.001$ \\
\hline Smoking & & & $<0.001$ \\
\hline Non-smoker & $210(54.4 \%)$ & $101(86.3 \%)$ & \\
\hline Current smoker & $176(45.6 \%)$ & $16(13.7 \%)$ & \\
\hline
\end{tabular}

BP: blood pressure; SBP: systolic blood pressure; DBP: diastolic blood pressure; BMI: body mass index. *Obese includes obese class I, II, and III.

than the aforementioned numbers. Out of 507 participants, 42 $(8.3 \%)$ individuals were labeled in the first group, i.e. SBP $\geq$ $140 \mathrm{~mm} \mathrm{Hg}$ and/or DBP $\geq 90 \mathrm{~mm} \mathrm{Hg}$. After studying each gender alone, males showed a significantly higher prevalence of HBP $(\mathrm{P}<0.001)$ compared to females with a percentage of $10.6 \%$, while only $0.8 \%$ of females were found to have HBP (Table 2).
BMI measurements showed unpleasant results (Fig. 1). The percentages of each category were as follows: underweight $(3.7 \%)$, normal $(30 \%)$, overweight $(36.7 \%)$, obese class I $(19.5 \%)$, obese class II $(6.2 \%)$, and obese class III $(3.9 \%)$. Unfortunately, almost two-thirds of the cases were overweight or obese. When we looked for gender relationship with BMI, we found statistically significant results $(\mathrm{P}<0.001)$. Of fe-

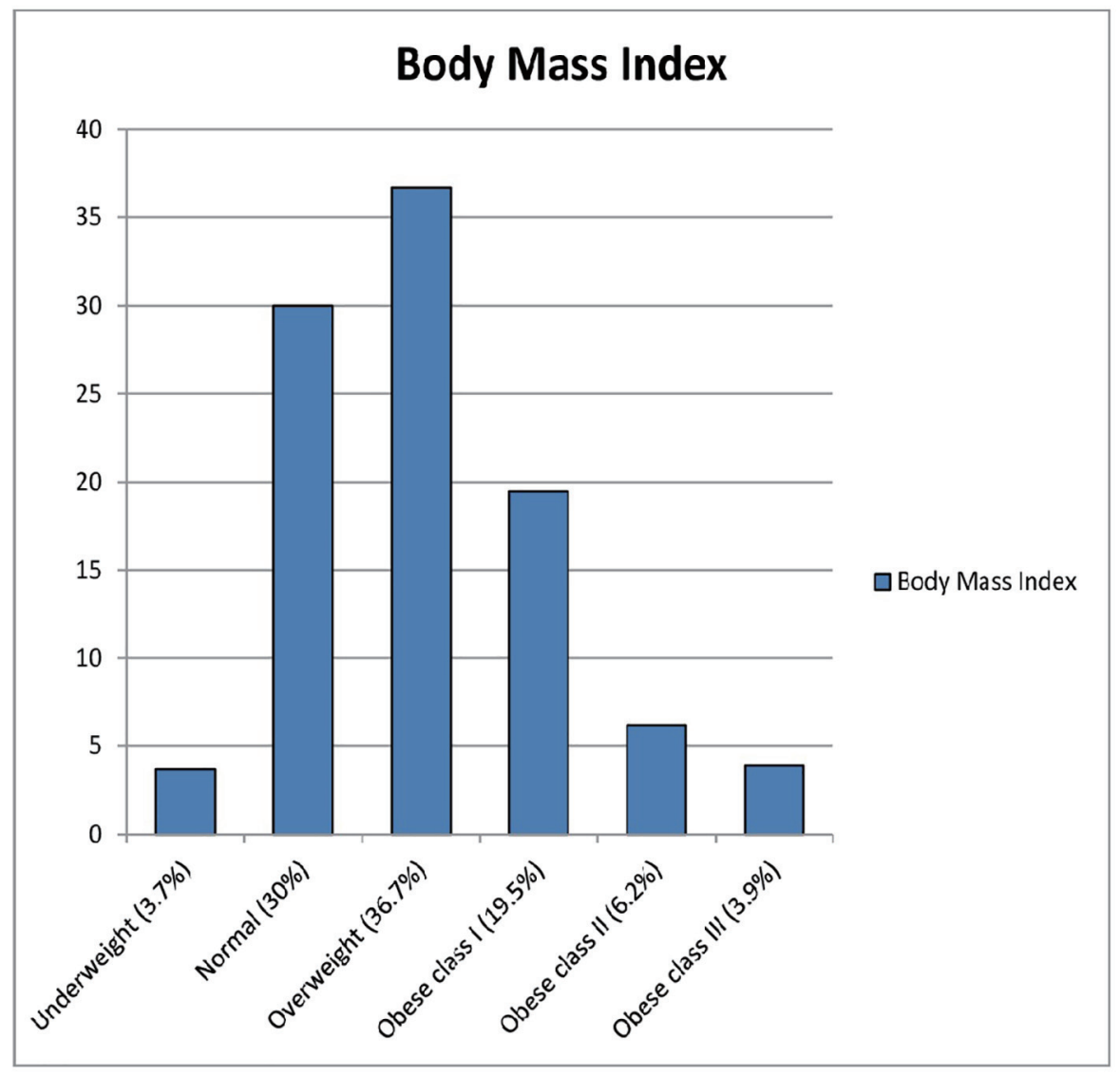

Figure 1. Body mass index of our sample: underweight $\left(<18.5 \mathrm{~kg} / \mathrm{m}^{2}\right)$, normal $\left(18.5-24.9 \mathrm{~kg} / \mathrm{m}^{2}\right)$, overweight $\left(25-29.9 \mathrm{~kg} / \mathrm{m}^{2}\right)$, obese class I $\left(30-34.9 \mathrm{~kg} / \mathrm{m}^{2}\right)$, obese class II $\left(35-39.9 \mathrm{~kg} / \mathrm{m}^{2}\right)$, and obese class III $\left(\geq 40 \mathrm{~kg} / \mathrm{m}^{2}\right)$. 
male cases, $53.3 \%$ were overweight or obese. However, males showed a much higher number regarding falling in overweight or obese categories with a percentage of $70.3 \%$ (Table 2 ). In conclusion, most of the sample had an abnormal BMI.

Regarding smoking, we divided the sample into smoker or non-smoker. We considered the individual as a smoker if he/she currently smokes cigarettes and/or Shisha. In our sample, $37.9 \%$ were smokers. Males showed a significantly higher percentage of being a current smoker $(\mathrm{P}<0.001)$. The percentages when we analyzed each gender alone were $45.5 \%, 13.3 \%$ among males and females, respectively (Table 2).

Blood glucose measurements were all random. Only three, two males and one female, out of 507 participants had an RBG of $\geq 200 \mathrm{mg} / \mathrm{dL}$ with a percentage of $0.6 \%$.

First-degree family history of DM and HTN was obtained by the questionnaire. Of the population, $45.3 \%$ had a positive family history of both, DM and HTN. The percentages of family history of DM only and HTN only were $14.6 \%$ and $12.9 \%$, respectively. First-degree family history of cardiac diseases was positive in $30 \%$ of the sample. These numbers can tell how prevalent these illnesses are in our community.

\section{Discussion}

General health is a concern to anyone but, unfortunately, there is less attention given to young populations regarding CVD risk factors. Also, young adults might have less care towards their general health. This neglect might be caused by low medical awareness about the possibility of being at risk to have CVD. In this study, we focused on young adults aged 20 - 40 years in order to approximately find the prevalence of undiagnosed cardiovascular risk factors. We excluded any diagnosed cases to eliminate bias.

After studying 507 participants for undiagnosed CVD risk factors, we found the prevalence of undiagnosed HBP to be $8.3 \%$ and males showed a significantly higher percentage $(\mathrm{P}<$ 0.001 ) when compared to females. Abnormal RBG prevalence was only $0.6 \%$. Regarding BMI, the prevalence of overweight and obesity together was $66.3 \%$ and males showed significantly higher percentage in falling in this category $(\mathrm{P}<0.001)$. Smoking prevalence was $37.9 \%$ with a significantly higher percentage among males $(\mathrm{P}<0.001)$. In addition, almost half of the sample had a positive first-degree family history of both DM and HTN. Moreover, almost one-third of them had a positive first-degree family history of CVD. Unfortunately, these numbers represent young adults, aged 20 - 40 years.

In the USA, regarding BP, the prevalence of undiagnosed HTN was around 5\% in 2011 - 2012 [17]. However, the prevalence of HBP was studied by many researchers from different countries around the world. Some studies showed variable percentages of HBP in previously undiagnosed individuals, such as $26 \%, 17.1 \%$, and $7.1 \%$ in Canada, Switzerland, and Brazil, respectively [18-20]. Locally, in the KSA, a national cross-sectional survey, conducted on people aged 15 - 64 in 2005 , showed $14.1 \%$ prevalence of HBP in unaware persons [21]. Other studies from different regions or cities were also reviewed. For example, in the Eastern province, a cross-sec- tional study was conducted on people aged 30 and above in 2005 . The prevalence stated by this study regarding previously undiagnosed HBP was 9\% [22]. In Riyadh, two studies were conducted and showed $11 \%$ and $10.7 \%$ prevalence rates [23, 24]. In Jeddah, two recent studies were also conducted. One of them was conducted on male university students and revealed a prevalence of $7.5 \%$ [25]. The other was conducted specifically on medical students and showed a prevalence of $9.3 \%$ [26]. Regardless of the differences in studies' populations and settings, our study prevalence of HBP was comparable with the aforementioned local studies.

In 2013, a national survey was conducted in the KSA to find the prevalence of current smoking status among individuals aged 15 and above. The result of this study revealed a $12.2 \%$ prevalence of current smoking in our kingdom [27]. Our study prevalence of current smoking was $37.9 \%$, which is almost the triple. This variation might be attributed to the specific age group of our study. Another variable, in our opinion, is that we were including Saudis and non-Saudis, unlike the abovementioned national survey.

Another national survey about obesity was conducted in 2013 on more than 10,000 participants. The prevalence rates of overweight and obesity together in this study were $57 \%$ and $60.9 \%$ representing males and females, respectively [28]. In our study, male percentage $(70.3 \%)$ was higher compared with aforementioned national study. On the other hand, female percentage was lower (53.3\%). Finally, regarding DM, a recent study was conducted in Jeddah revealed about $1.3 \%$ prevalence of confirmed DM in unaware persons [29]. In our study, $0.6 \%$ of our population had an $\mathrm{RBG} \geq 200 \mathrm{mg} / \mathrm{dL}$.

In the present study, although we invited both genders to participate and offered male or female counters, there was a big difference in our study's sex distribution. Males number was almost triple the number of females. Our assumption to explain this difference is that there were mostly male attendees with patients, which is usual in our country. The other limitation we faced is that we could not make a definitive diagnosis of HTN or DM from only 1 day readings $[14,16]$. Hence, we referred to any abnormal reading as high $\mathrm{BP}$ or high $\mathrm{RBG}$, which are found to be risk factors [30].

\section{Acknowledgments}

We would like to thank King Abdullah International Medical Research Center for sponsoring our research. Also, we acknowledge Dr. Anwar Khan, Dr. Ahmed Alfaidi, and Dr. Hamed Aljeffri for reviewing and giving valuable advices.

\section{Funding}

No funding was received for this study.

\section{Conflicts of Interest}

All authors have no conflicts of interest to manipulate the find- 
ings.

\section{Author Contributions}

All student authors were involved in every step of the study. Doctor authors were involved in supervising all steps of the research and provide guidance and solutions to encountered hurdles.

\section{References}

1. WHO. Global Status Report on Noncommunicable Diseases 2014. World Health Organization. 2014.

2. Lozano R, Naghavi M, Foreman K, Lim S, Shibuya K, Aboyans V, Abraham J, et al. Global and regional mortality from 235 causes of death for 20 age groups in 1990 and 2010: a systematic analysis for the Global Burden of Disease Study 2010. Lancet. 2012;380(9859):2095-2128.

3. Smith SC Jr. Multiple risk factors for cardiovascular disease and diabetes mellitus. Am J Med. 2007;120(3 Suppl 1):S3-S11.

4. Daviglus ML, Talavera GA, Aviles-Santa ML, Allison M, Cai J, Criqui MH, Gellman M, et al. Prevalence of major cardiovascular risk factors and cardiovascular diseases among Hispanic/Latino individuals of diverse backgrounds in the United States. JAMA. 2012;308(17):1775-1784.

5. Pessinaba S, Mbaye A, Yabeta GA, Kane A, Ndao CT, Ndiaye MB, Harouna $\mathrm{H}$, et al. Prevalence and determinants of hypertension and associated cardiovascular risk factors: data from a population-based, cross-sectional survey in Saint Louis, Senegal. Cardiovasc J Afr. 2013;24(5):180-183.

6. Paquissi FC, Manuel V, Manuel A, Mateus GL, David B, Beu G, Castela A. Prevalence of cardiovascular risk factors among workers at a private tertiary center in Angola. Vasc Health Risk Manag. 2016;12:497-503.

7. Yamout R, Adib SM, Hamadeh R, Freidi A, Ammar W. Screening for cardiovascular risk in asymptomatic users of the primary health care network in Lebanon, 20122013. Prev Chronic Dis. 2014;11:E120.

8. Korhonen PE, Kautiainen H, Mantyselka P. Screening for cardiovascular risk factors and self-rated health in a community setting: a cross-sectional study in Finland. Br J Gen Pract. 2014;64(627):e611-615.

9. WHO. Saudi Arabia, Noncommunicable Diseases (NCD) Country Profiles. World Health Organization. 2014.

10. Ai-Shahri MZ. Health and lifestyle: a saudi profile. J Family Community Med. 1996;3(2):13-21.

11. Midhet F, Al Mohaimeed AR, Sharaf F. Dietary practices, physical activity and health education in qassim region of saudi arabia. Int J Health Sci (Qassim). 2010;4(1):3-10.

12. Ghabrah TM, Bahnassy AA, Abalkhail BA, Al-Bar HM, Milaat WA. The prevalence of cardiovascular risk factors among students in jeddah, saudi arabia. J Family Community Med. 1997;4(2):55-63.

13. Pickering TG, Hall JE, Appel LJ, Falkner BE, Graves J, Hill MN, Jones DW, et al. Recommendations for blood pressure measurement in humans and experimental animals: Part 1: blood pressure measurement in humans: a statement for professionals from the Subcommittee of Professional and Public Education of the American Heart Association Council on High Blood Pressure Research. Hypertension. 2005;45(1):142-161.

14. James PA, Oparil S, Carter BL, Cushman WC, Dennison-Himmelfarb C, Handler J, Lackland DT, et al. 2014 evidence-based guideline for the management of high blood pressure in adults: report from the panel members appointed to the Eighth Joint National Committee (JNC 8). JAMA. 2014;311(5):507-520.

15. Obesity: preventing and managing the global epidemic. Report of a WHO consultation. World Health Organ Tech Rep Ser. 2000;894:i-xii, 1-253.

16. WHO. Definition and Diagnosis of Diabetes Mellitus and Intermediate Hyperglycaemia. Geneva: World Health Organization, 2006.

17. Nwankwo T, Yoon SS, Burt V, Gu Q. Hypertension among adults in the United States: National Health and Nutrition Examination Survey, 2011-2012. NCHS Data Brief. 2013;133:1-8.

18. Joffres MR, Hamet P, Rabkin SW, Gelskey D, Hogan K, Fodor G. Prevalence, control and awareness of high blood pressure among Canadian adults. Canadian Heart Health Surveys Research Group. CMAJ. 1992;146(11):19972005.

19. Walther D, Curjuric I, Dratva J, Schaffner E, Quinto C, Rochat T, Gaspoz JM, et al. High blood pressure: prevalence and adherence to guidelines in a population-based cohort. Swiss Med Wkly. 2016;146:w14323.

20. Chor D, Pinho Ribeiro AL, Sa Carvalho M, Duncan BB, Andrade Lotufo P, Araujo Nobre A, Aquino EM, et al. Prevalence, awareness, treatment and influence of socioeconomic variables on control of high blood pressure: results of the ELSA-Brasil Study. PLoS One. 2015;10(6):e0127382.

21. Saeed AA, Al-Hamdan NA, Bahnassy AA, Abdalla AM, Abbas MA, Abuzaid LZ. Prevalence, awareness, treatment, and control of hypertension among Saudi adult population: a national Survey. Int J Hypertens. 2011;2011:174135.

22. Al-Turki KA, Al-Baghli NA, Al-Ghamdi AJ, El-Zubaier AG. Hypertension in the eastern province of saudi arabia: results of a screening campaign. J Family Community Med. 2008;15(3):95-101

23. Mitwalli AH, Harthi AA, Mitwalli H, Juwayed AA, Turaif NA, Mitwalli MA. Awareness, attitude, and distribution of high blood pressure among health professionals. J Saudi Heart Assoc. 2013;25(1):19-24.

24. Alsuwaida A, Alghonaim M. Gender disparities in the awareness and control of hypertension. Clin Exp Hypertens. 2011;33(5):354-357.

25. Baig M, Gazzaz ZJ, Gari MA, Al-Attallah HG, AlJedaani KS, Mesawa AT, Al-Hazmi AA. Prevalence of obesity and hypertension among University students' and their knowledge and attitude towards risk factors of Cardiovascular Disease (CVD) in Jeddah, Saudi Arabia. Pak J Med Sci. 2015;31(4):816-820. 
26. Ibrahim NK, Mahnashi M, Al-Dhaheri A, Al-Zahrani B, Al-Wadie E, Aljabri M, Al-Shanketi R, et al. Risk factors of coronary heart disease among medical students in King Abdulaziz University, Jeddah, Saudi Arabia. BMC Public Health. 2014;14:411.

27. Moradi-Lakeh M, El Bcheraoui C, Tuffaha M, Daoud F, Al Saeedi M, Basulaiman M, Memish ZA, et al. Tobacco consumption in the Kingdom of Saudi Arabia, 2013: findings from a national survey. BMC Public Health. 2015;15:611.

28. Memish ZA, El Bcheraoui C, Tuffaha M, Robinson M, Daoud F, Jaber S, Mikhitarian S, et al. Obesity and as- sociated factors - Kingdom of Saudi Arabia, 2013. Prev Chronic Dis. 2014;11:E174.

29. Bahijri SM, Jambi HA, Al Raddadi RM, Ferns G, Tuomilehto J. The Prevalence of Diabetes and Prediabetes in the Adult Population of Jeddah, Saudi Arabia - A Community-Based Survey. PLoS One. 2016;11(4):e0152559.

30. Balkau B, Shipley M, Jarrett RJ, Pyorala K, Pyorala M, Forhan A, Eschwege E. High blood glucose concentration is a risk factor for mortality in middle-aged nondiabetic men. 20-year follow-up in the Whitehall Study, the Paris Prospective Study, and the Helsinki Policemen Study. Diabetes Care. 1998;21(3):360-367. 